\title{
ORDEM ECONÔMICA CONSTITUCIONAL, TRIBUTAÇÃO E FUNÇÃO SOCIAL DA EMPRESA: A EXIGÊNCIA DE QUITAÇÃO DE TRIBUTOS COMO REQUISITO PARA DEFERIMENTO DA RECUPERAÇÃO JUDICIAL
}

\author{
CONSTITUTIONAL ECONOMIC ORDER, TAXATION AND SOCIAL FUNCTION OF THE \\ COMPANY: THE REQUIREMENT OF PAYMENT OF TAXES AS A REQUIREMENT FOR \\ DEFERRAL OF JUDICIAL RECOVERY
}

Vinícius Klein

Doutor em Direito Civil pela UERJ Doutor em Desenvolvimento Econômico pela UFPR. Visiting Scholar na Universidade de Columbia/EUA em 2012 Procurador do Estado do Paraná Professor Adjunto no Departamento de

Economia da UFPR lecionando a disciplina de Economia e Direito no curso de graduação em economia e de Economia e Estado no mestrado profissional em desenvolvimento econômico viniciusklein78@yahoo.com.br

Eduardo Castro

Mestre em Direito do Estado (Direito Tributário) pela Universidade Federal do Paraná - UFPR - Professor Substituto de Direito Empresarial e Direito Tributário no Departamento de Administração da UFPR eduardodecastro@hotmail.com

Recebido em: 19/12/2018 Aprovado em: 27/06/2019

RESUMO: O artigo tem por objetivo investigar a validade das regras contidas nos artigos 191A, do Código Tributário Nacional (incluído pela Lei Complementar n. 118, de 2005), e 57, da Lei n. 11.101, de 2005 (Lei de Recuperação de Empresas), que condicionam a concessão da recuperação judicial à prova, pela empresa postulante, de quitação ou de suspensão da exigibilidade de todos créditos tributários inscritos em dívida ativa. O estudo é realizado a partir de uma análise crítica do modelo de Estado Social adotado pelo Constituinte em 1988, bem como à luz dos princípios gerais que regem a atividade econômica, com destaque para os princípios da livre iniciativa, da valorização do trabalho e da função social da propriedade privada.O problema enfrentado é o seguinte: Estão em conformidade com a Constituição de 1988 as prescrições legais que condicionam a concessão da recuperação judicial à quitação - ou à suspensão da exigibilidade - de todos os tributos porventura devidos pela empresa em crise? A hipótese que se vai investigar é a de que, ainda que a ordem econômica constitucional reconheça - e proteja certos valores tipicamente liberais, em especial livre iniciativa, livre concorrência e propriedade privada, não há como se reputar contrária à Constituição a escolha, levada a efeito pelo legislador ordinário, de não dispensar a empresa em crise do cumprimento das obrigações tributárias por ela contraídas. O método científico utilizado é o hipotético-dedutivo.

Palavras-chave: Recuperação judicial; atividade econômica; tributação. 
ABSTRACT: The purpose of this article is to investigate the validity of the rules contained in Article 191-A of the National Tax Code (included in Complementary Law 118, 2005) and article 57, of the Law 11.101, 2005, which condition the grant of judicial recovery to the proof, by the postulant company, of discharge of all taxes inscribed in active debt. The study is based on a critical analysis of the Social State model adopted by the Constituent Assembly in 1988, as well as in the light of the general principles that govern economic activity, with emphasis on the principles of free enterprise, valorization of work and social function of private property. The problem faced is the following: Are the legal provisions that condition the granting of judicial recovery to the discharge - or suspension - of all taxes due by the company in accordance with the 1988 Constitution?The hypothesis that we are going to investigate is that, although the constitutional economic order recognizes - and protects - certain typically liberal values, such as free initiative, free competition and private property, it is not possible to be considered contrary to the Constitution to choose not to exempt the company in crisis from complying with its tax obligations. The scientific method used is hypothetical-deductive.

Keywords: Judicial reorganization; economic activity; taxation.

SUMÁRIO: 1. Introdução; 2.Estadodemocrático e social de direito, ordem econômica constitucional e função social da empresa; 3. Falência e recuperação de empresas como instrumentos de proteção da ordem econômica constitucional;4. A dívida tributária como obstáculo à recuperação da empresa; 5. Solidariedade, dever fundamental de pagar tributos e a composição dos interesses fazendários no curso do processo de recuperação judicial; 6. Conclusão; 7. Referências.

\section{INTRODUÇÃO}

O Código Tributário Nacional, em seu art. 191-A, e a Lei n. 11.101, de 9 de fevereiro de 2005, doravante denominada Lei de Recuperação de Empresas (LRE), em seu art. 57, caput, condicionam o deferimento da Recuperação Judicial à prova de quitação - ou de suspensão - de todos os débitos tributáriospela empresa em crise.

Asprescrições acima têm gerado profundas divergências doutrinárias e jurisprudenciais, controvertendo-se, em regra, sobre a validade do referido dispositivo à luz das disposições constitucionais que regem a atividade econômica. De um lado, encontram-se aqueles que, como Machado (2005, p. 69), entendem que a exigência de quitação de tributos por parte de entidades que reconhecidamente se encontram em situação de dificuldade econômico-financeira contraria os princípios constitucionais da livre iniciativa e da função social da propriedade privada; de outro, aqueles que, como Pisani (2015), embora reconheçam a relevância da atividade empresarial para o desenvolvimento nacional, defendem a manutenção da referida regra, considerando, sobretudo, a importância do cumprimento do dever fundamental de pagar tributos para a concretização dos objetivos fundamentais republicanos, estabelecidos no art. $3^{\circ}$ da Constituição de 1988. No âmbito dos Tribunais, a divergência também se faz presente, já tendo sido até mesmo ajuizada - pelo Distrito Federal -Ação Declaratória de Constitucionalidade $\left(\mathrm{ADC} 46^{1}\right)$ com vistas ao reconhecimento da validade do supracitado art. 57 da LRE.

O que se vai analisar no presente artigo é justamente esse (aparente) conflito, verificado na grande maioria dos processos de recuperação judicial, entre livre exercício da atividade econômica e tributação.

${ }^{1} \mathrm{O}$ processo está pendente de julgamento.

Revista de Direito Brasileira | Florianópolis, SC | v. 23 | n. 9 | p. 410-424 |Mai./Ago. 2019 
O problema que se vai tentar responder ao longo das próximas páginas é o seguinte: São válidas as prescrições legais que condicionam a concessão da recuperação judicial à quitação ou à suspensão da exigibilidade - de todos os tributos porventura devidos pela empresa em crise?

A hipótese que se vai investigar é a de que, ainda que a ordem econômica constitucional reconheça - e proteja - certos valores tipicamente liberais, como livre iniciativa, livre concorrência e propriedade privada, não há como reputar contrária à Constituição a escolha, levada a efeito pelo legislador ordinário, de não dispensar a empresa em crise do cumprimento das obrigações tributárias por ela contraídas.

O método científico utilizado é o hipotético-dedutivo, compreendido, nas palavras de Marconi e Lakatos (2011, p. 71), como aquele em que o estudo parte "do problema e da conjectura, que serão testados pela observação e experimentação”. A pesquisa será realizada prioritariamente a partir da análise da literatura especializadano estudo da ordem constitucional econômica e da ordem constitucional tributária. Os julgados do Superior Tribunal de Justiça e do Supremo Tribunal Federal mencionados no texto, importante esclarecer, servem apenas para ilustrar de que maneira a hipótese contrária que se pretende refutar vem sendo utilizada pelos órgão de aplicação do Direto, não havendo qualquer pretensão de se realizar um estudo exaustivo - ou mesmo estatístico - da jurisprudência das Cortes Superiores sobre o tema.

Para tanto, adotar-se-á o seguinte percurso, já iniciado por meio desta introdução: na Seção 2, discorrer-se-á sobre a ordem econômico-social normativa - também denominada ordem do "dever ser" (GRAU, 2012, p. 66) - inaugurada em 1988, conferindo-se especial atenção às características básicas do Estado Democrático e Social de Direito e aos princípios gerais que regem a atividade econômica; na Seção 3, tratar-se-á especificamente dos institutos da falência e da recuperação de empresas, ambos considerados instrumentos de regulação do mercado; na Seção 4, serão demonstradas as diferentes correntes de pensamento referentes à validade (ou invalidade) das exigências legais de quitação de tributos como requisito indispensável à concessão da recuperação judicial; por fim, discorrer-se-á sobre o conflito aparente entre tributação e livre exercício de atividade econômica, oportunidade em que serão tecidas considerações sobre a relevância do dever fundamental de pagar tributos em um Estado Democrático e Social de Direito.

Dado o escopo do presente trabalho, não serão realizadas considerações sobre as divergências referentes aos limites dos poderes do juiz no processo de recuperação judicial, bem como sobre os efeitos econômicos das decisões judiciais - em especial, aquelas de lavra do Superior Tribunal de Justiça - que conferem ao referido magistrado amplos poderes para decidir sobre a viabilidade econômica de empresa em crise, inclusive mediante suspensão de atos de constrição determinados em sede de execução fiscal. O instituto da recuperação extrajudicial, por sua vez, será tratado em algumas passagens, mas apenas lateralmente.

\section{ESTADO DEMOCRÁTICO E SOCIAL DE DIREITO, ORDEM ECONÔMICA CONSTITUCIONAL E FUNÇÃO SOCIAL DA EMPRESA.}

Da análise dos objetivos fundamentais da República, positivados no art. $3^{\circ}$ da Constituição de 1988, bem como dos numerosos direitos sociais, econômicos e culturais estabelecidos ao longo de toda a Carta Constitucional, percebe-se claramente a opção do Constituinte originário por um modelo de Estado que não se identifica com todos os ideais liberais clássicos, verificados sobretudo na Europa ocidental no final do século XIX e no início do século XX (BITENCOURT NETO, 2017). Ao estabelecer que é atribuição da República Federativa do Brasil "construir uma sociedade livre, justa e solidária", "garantir o desenvolvimento nacional”, "erradicar a pobreza e a marginalização e reduzir as desigualdades sociais e regionais", bem como "promover o bem de todos, sem preconceitos de origem, raça, 
sexo, cor, idade e quaisquer outras formas de discriminação", a Constituição sepulta toda e qualquer pretensão de um Estado mínimo, meramente garantidor (CASTRO, 2016, p. 120).

No Estado Liberal clássico, confere-se primazia aos chamados direitos de primeira dimensão, relacionados aos ideais de liberdade e igualdade (meramente formal), como os direitos à vida, privacidade, intimidade e propriedade (GRAU, 2012, p. 772). Nesse modelo, espera-se do Estado que se imiscua o mínimo possível na vida dos cidadãos, limitando-se, sempre que possível, a garantir a segurança necessária ao desenvolvimento de suas atividades individuais.

O Estado Liberal foi concebido como o modelo ideal ao desenvolvimento do capitalismo, na medida em que se propõe, prioritariamente, a fornecer as condições necessárias à circulação e à acumulação de riquezas.

Ocorre que essa reduzida intervenção do Estado nas atividades privadas permitiu um quadro de forte concentração de renda nas mãos de poucos e, consequentemente, piora na qualidade de vida da massa dos trabalhadores. A desigualdade proporcionada pelo Estado mínimo liberal, no início do Século XX, era de tal monta, que, às vésperas da Primeira Guerra Mundial, na França, durante a fase final da chamada belle époque, a parcela do décimo superior passou de 50\% da renda nacional (PIKETTY, 2014, p. 265). Nas lições de Bonavides (1996, p. 188), “[o] velho liberalismo, na estreiteza de sua formulação habitual, não pôde resolver o problema essencial de ordem econômica das vastas camadas proletárias da sociedade, e por isso entrou irremediavelmente em crise".

Nesse cenário, ganharam força, sobretudo entre as camadas populares, os ideais de teóricos socialistas, contrários à propriedade privada dos meios de produção e à exploração do proletariado pelos empregadores, com destaque para Karl Marx e Friedrich Engels. Em fevereiro de 1917, na Rússia, foi destituído do cargo o último Czar a governar o país; em outubro do mesmo ano, o Partido Bolchevique derrubou o governo provisório e deu início ao maior regime socialista jamais visto.

Como medida de reconhecimento dos anseios dos economicamente menos favorecidos, bem como com vistas à manutenção do regime capitalista de produção, foram promulgadas, no México e na Alemanha, em 1917 e 1919, respectivamente, as Cartas Constitucionais que inauguraram aquilo que se convencionou chamar de Estado Social. Nesse novo modelo institucional, organizado em função da sociedade e não mais do indivíduo, embora mantidas a propriedade privada dos meios de produção e a licitude da busca pelos lucros decorrentes da exploração dessa propriedade, passou-se a verificar uma participação muito mais ativa do Poder Público, o que envolvia uma atuação não apenas indutiva, mas também corretiva do Estado (BITENCOURT NETO, 2017). Aqui, nas palavras de Lima e Oliveira (2018, p. 228), “[o] modelo econômico liberal, asilado por aquele Estado inerte à regulamentação das relações sociais, dá lugar ao modelo econômico respaldado pela intervenção estatal, em que o Estado passa a ser agente regulador das atividades econômicas e das relações de trabalho".

Era preciso reorganizar as instituições de forma que o capitalismo não sucumbisse às investidas socialistas, chegando Bonavides (1995, p. 224) a fazer menção a um "recuo estratégico, cujas resultantes foram as largas revisões e modificações introduzidas tanto nas órbitas formais como materiais da nova realidade constitucional". Para sobreviver, "o Estado burguês se adapta a certas condições históricas; ora recua, ora transige, ora vacila" (BONAVIDES, 1996, p. 183).De acordo com Copetti Neto e Garcia (2017, p 138), "a partir das pautas trazidas pelo socialismo, o liberalismo passa a enfrentar o seu maior desafio: conciliar a liberdade econômica com a justiça social". Foram consagrados, no Estado Social, os direitos sociais, também conhecidos como direitos de segunda dimensão, referentes à educação, à saúde, à previdência e às relações de trabalho. Esses direitos sociais tornaram possível o nascimento da consciência de que a proteção da instituição, uma realidade social aberta à participação popular criativa e à valoração da personalidade, era tão - ou até mais - importante quanto salvaguardar os interesses individuais (BONAVIDES, 2013, p. 583). 
A exacerbação das funções do Estado Social, no entanto, acabou por levá-lo também ao declínio, sobretudo em razão dos problemas financeiros decorrentes desse atuar tão intenso. A solidariedade almejada passou a ser construída muito mais por obra do Poder Público do que dos próprios cidadãos, falando-se, em razão disso, em uma solidariedade vertical, ou solidariedade do Estado em relação à sociedade (SEPULCRI, 2013, p. 40-41). Tornava-se imprescindível, assim, alcançar um modelo institucional intermediário entre o Estado liberal clássico e o insustentável Estado de providência, de forma que, mantidos os direitos de primeira dimensão, não fossem perdidas as grandes conquistas sociais decorrentes do advento deste último.

Nasce, nesse cenário, o Estado Democrático e Social de Direito, também conhecido como Estado Subsidiário, em que ao Ente Público passa a ser conferida a missão predominante de coordenação das ações e decisões coletivas, com vistas a que todos, solidariamente, isto é, em regime de mútuo apoio, possam desenvolver-se em sua plenitude (MOREIRA NETO, 2011, p. 29). Reduz-se, aqui, a intervenção econômica estatal, sobretudo por meio da transferência de determinadas tarefas públicas a particulares (delegações e concessões) ou mesmo dos processos de privatizações, tudo com vistas à maior participação dos agentes da sociedade civil na vida pública (GUERRA FILHO, 2005, p. 24).A solidariedade, no Estado Democrático e Social, diferentemente do que acontece nos chamados Estados Liberal e Social, é multidimensional, ou seja, depende tanto da participação ativa do Estado quanto da sociedade civil, numa relação de interdependência. Pode-se falar, nesse caso, em solidariedade horizontal (SEPULCRI, 2013, p. 41-42).

Conforme exposto, a Constituição de 1988, ao discriminar objetivos como erradicação da pobreza e da marginalização e consagrar extenso rol de direitos sociais, econômicos e culturais, ao contrário de Cartas Constitucionais de viés mais liberal, como a dos Estados Unidos, por exemplo, elimina qualquer dúvida acerca da opção do constituinte originário por um modelo institucional de forte socialidade, o que não impossibilita, e isso deve ficar claro, a proteção de numerosos valores liberais - como propriedade privada, livre iniciativa e livre concorrência -, bem comoa adoção das premissas básicas do Estado Democrático e Social. Em verdade, ao impor que a efetivação desse ideal de socialidade se dê num ambiente de pluralismo político, a Carta Constitucional afasta a conclusão de que só exista um modo adequado para concretização desse Estado Social. O que não se admite de maneira alguma é a possibilidade de um arranjo institucional consentâneo com as premissas do Estado Liberal clássico (BITENCOURT NETO, 2017).

O ideal de solidariedade horizontal, segundo o qual também a sociedade civil deve contribuir para o alcance dos objetivos republicanos, pode ser notado em diversas passagens da Lex Suprema, como no caso do dever fundamental de pagar impostos (art. 145, $\S 1^{\circ}$ ), do dever dos familiares de cuidar das crianças, adolescentes e jovens (art. 227), e do serviço militar obrigatório (art. 143). A construção doutrinária da eficácia horizontal dos direitos fundamentais, segundo a qual os direitos fundamentais são oponíveis não apenas ao Estado, mas também aos demais cidadãos (MENDES; COELHO; BRANCO, 2010, p. 353 e ss.) (MARMELSTEIN, 2016, p. 342 e ss.) (SARLET; MARINONI; MITIDIERO, 2013, p. 335 e ss.), apenas reforça o exposto anteriormente. A sociedade almejada, além de livre e justa, deve ser solidária.

Como não poderia deixar de ser, também a ordem econômica positivada na Constituição de 1988 reflete a opção por um modelo de Estado que fomenta a solidariedade horizontal, na medida em que, a um só tempo, garante a propriedade privada dos meios de produção e a livre iniciativa como pilares de seu desenvolvimento, e inclui entre seus princípios fundamentais a função social da propriedade, a livre concorrência, a defesa do consumidor e do meio ambiente, a redução das desigualdades regionais e sociais, a busca do pleno emprego e o tratamento favorecido para as empresas de pequeno porte (art. 170, incisos III, IV, V, VI, VII, VIII e IX). Autoriza-se a busca pelo lucro, mas dentro de certos limites. 
A ordem econômica desejada, fundada na livre iniciativa e na valorização do trabalho humano, tem por desiderato assegurar a todos uma existência digna conforme os ditames da justiça social (CF/88, art. 170, caput). A liberdade irrestrita de troca e o lucro desmesurado, como se percebe, sucumbem diante de outros valores juridicizados, como a promoção da igualdade material e a dignidade do trabalhador (LIMA, OLIVEIRA, 2018).

A liberdade de exercício da atividade econômica, tal como prevista na Constituição, pode ser limitada e regulada pela atuação estatal, no exercício de seu poder de polícia administrativa, sempre que isso se revele benéfico ao interesse maior da coletividade (FIGUEIREDO, 2011, p. 65-66). Como ensina Salomão Filho (2011, p. 93-94), "livre-iniciativa não é sinônimo de liberdade econômica absoluta", mas, sim, uma "cláusula geral cujo conteúdo é preenchido pelos incisos do mesmo artigo". Até a propriedade privada, direito fundamental de primeira dimensão, deve ser interpretada à luz de um contexto mais amplo de um Estado Democrático e Social (FACHIN, 2006, p. 47). Nesse sentido, não só a Constituição de 1988 dispõe sobre a função social da propriedade (art. $5^{\circ}$, XXIII, e art. 170, III), mas também o Código Civil de 2002, que prescreve que "[o] direito de propriedade deve ser exercido em consonância com as suas finalidades econômicas e sociais e de modo que sejam preservados... a flora, a fauna, as belezas naturais, o equilíbrio ecológico e o patrimônio histórico e artístico" (art. 1.228, $\S 1^{\circ}$ ). Referido diploma normativo estabelece ainda que "[s]ão defesos os atos que não trazem ao proprietário qualquer comodidade, ou utilidade, e sejam animados pela intenção de prejudicar outrem" (art. 1.228, § $2^{\circ}$ ).

Da concepção de função social da propriedade, surge o princípio da função social da empresa, de acordo com o qual também o exercício profissional da atividade econômica organizada para a produção ou a circulação de bens ou de serviços deve ser exercido com vistas não só ao lucro de seu titular, mas ao bem da coletividade. Não obstante estar autorizado a lucrar, compete ao titular da empresa respeitar os direitos doconsumidor e o meio ambiente, promover o desenvolvimento social e a emancipação da classe trabalhadora e recolher os tributos criados por lei (SILVA, 2017).O princípio da função social da empresa é normativamente reconhecido há bastante tempo. O art. 116, parágrafo único, da Lei n. 6.404, de 1976 (Lei de Sociedades Anônimas), estabelece que "[o] acionista controlador deve usar o poder com o fim de fazer a companhia realizar o seu objeto e cumprir sua função social, e tem deveres e responsabilidades para com os demais acionistas da empresa, os que nela trabalham e para com a comunidade em que atua, cujos direitos e interesses deve lealmente respeitar e atender". O art. 154, caput, do mesmo diploma normativo, por sua vez, dispõe que "[o] administrador deve exercer as atribuições que a lei e o estatuto lhe conferem para lograr os fins e no interesse da companhia, satisfeitas as exigências do bem público e da função social da empresa".

A Lei n. 11.101, de 2005, além de dispor expressamente sobre o princípio da função social da empresa, trouxe ao ordenamento jurídico a ideia de preservação da empresa (art. 47), reconhecendo a importância de se preservar a atividade empresarial e seus inegáveis dividendos sociais, como geração de emprego, aumento da renda familiar e recolhimento de tributos (CAMPINHO, 2012, p. 182). Nas palavras de Fachin (2006, p. 186), "[o] princípio da preservação da empresa interessa ao Direito e à Economia, pela proteção que oferece à continuidade dos negócios sociais. Tal preservação da empresa tem uma notável importância".

Dentre os instrumentos de preservação da atividade empresarial e proteção da ordem econômica constitucional, destacam-se a falência e a recuperação de empresas (judicial e extrajudicial), a respeito dos quais se discorrerá adiante.

\section{FALÊNCIA E RECUPERAÇÃO DE EMPRESAS COMO INSTRUMENTOS DE PROTEÇÃO DA ORDEM ECONÔMICA CONSTITUCIONAL}


A ordem econômica do Estado Democrático e Social de Direito brasileiro, como visto, embora reconheça o direito à propriedade privada - e à obtenção de lucros com a exploração dessa propriedade -, vaticina que a atividade econômica seja exercida em benefício de toda a coletividade,cabendo ao agente econômico, dentre outros deveres, recolher aos cofres públicos os tributos devidos, respeitar os direitos dos consumidores e trabalhadores, assim como preservar o meio ambiente para as gerações futuras, daí falar-se em função social da propriedade.

Foi com o objetivo de maximizar a referida função social que se editou a Lei n. 11.101, de 2005, conhecida como Lei de Recuperação de Empresas - LRE, diploma regulador dos institutos da recuperação judicial, da recuperação extrajudicial e da falência.Enquanto a recuperação judicial tem por objetivo "viabilizar a superação da situação de crise econômicofinanceira do devedor, a fim de permitir a manutenção da fonte produtora, do emprego dos trabalhadores e dos interesses dos credores, promovendo, assim, a preservação da empresa, sua função social e o estímulo à atividade econômica" (LRE, art. 47), a falência, "ao promover o afastamento do devedor de suas atividades, visa a preservar e otimizar a utilização produtiva dos bens, ativos e recursos produtivos, inclusive os intangíveis, da empresa" (LRE, art. 75, caput).

O processo de recuperação judicial, portanto, ao reconhecer a importância da preservação da atividade empresarial, "fonte produtora de bens, serviços, empregos e tributos que garantem o desenvolvimento econômico e social de um país" (CAMPINHO, 2012, p. 126), destina-se a agentes econômicos passíveis de recuperação, enquanto a falência destina-se ao encerramento das atividades de empresários e sociedades empresárias inequivocamente insolventes e, em sendo possível, à continuidade da atividade econômica por outros agentes.

A recuperação judicial, dessa forma, não pode ser enxergada como um fim em si mesmo, além disso, nem toda falência configura um mal. Determinadas empresas, por serem desorganizadas, tecnologicamente atrasadas ou descapitalizadas, devem ter suas atividades encerradas, para o bem da coletividade, de forma que os recursos nelas empregados possam ser realocados de maneira mais benéfica à sociedade como um todo. A falência das sociedades despreparadas é fundamental para a continuidade das empresas socialmente responsáveis (COELHO, 2013, p. 161).

Na esteira do que ensina Coelho (2011, p. 161), “[q]uando o aparato estatal é utilizado para garantir a permanência de empresas insolventes inviáveis, opera-se uma inversão inaceitável: o risco da atividade empresarial transfere-se do empresário para os seus credores". Ainda de acordo com o renomado professor, "[a] recuperação judicial não pode significar (...) a substituição da iniciativa privada pelo juiz na busca de soluções para a crise da empresa" (COELHO, 2013, p. 164).

$\mathrm{Na}$ recuperação judicial, ao contrário do que ocorria à época da vigência do vetusto instituto da concordata, regido pelo Decreto-Lei n. 4.661, de 1945,confere-se protagonismo a diversas classes de credores da empresa em situação de dificuldade financeira, que irão deliberar sobre a viabilidade do plano de recuperação apresentado e, em sendo o caso, sujeitar-se às novas condições de pagamento propostas. Nas palavras de Garcia e Sant Anna (2017), “[c]om o pedido de recuperação judicial, o devedor coloca-se em posição de negociação pública da sua dívida, sob a supervisão e a fiscalização do Poder Judiciário, do Ministério Público e de todos os seus stakeholders".

A solução para a crise empresarial depende do equilíbrio entre interesses privados, públicos e coletivos (CAMPINHO, 2012, p. 126). O Estado só deve contribuir para a preservação de agentes econômicos viáveis e capazes, restando aos empreendedores desonestos ou irrecuperáveis financeira ou economicamente a decretação da falência (CAMPINHO, 2012, p. 128). Conforme Fornari (2016), "o esforço coletivo para tentar salvar a empresa, nessas hipóteses, não compensou os custos sociais impostos e, nesse quesito, o Estado-juiz deve colocar ordem no caos". 
O plano de recuperação deve conter os meios pelos quais a sociedade pretende se recuperar, o que inclui, exemplificativamente, "concessão de prazos e condições especiais para pagamento das obrigações vencidas ou vincendas", "alteração do controle societário" e "substituição total ou parcial dos administradores do devedor ou modificação de seus órgãos administrativos" (LRE, art. 50, incisos I, III e V). Não havendo um consenso mínimo (legalmente estabelecido), a recuperação não terá êxito e a atividade empresarial cessará.

Ocorre que, ao disciplinar o procedimento recuperacional, o legislador optou por excluir determinados créditos dos efeitos da recuperação judicial. Dentre esses créditos, destacam-se aqueles de "credor titular da posição de proprietário fiduciário de bens móveis ou imóveis, de arrendador mercantil, de proprietário ou promitente vendedor de imóvel cujos respectivos contratos contenham cláusula de irrevogabilidade ou irretratabilidade" (LRE, art. 49, $\S 3^{\circ}$ ), bem como os créditos de titularidade da Fazenda Pública.

É sobre as disposições que impedem o credor público de transigir no âmbito do processo recuperacional, assim como as que condicionam o deferimento da recuperação à quitação do passivo tributário pela empresa em crise, que iremos discorrer adiante.

\section{A DÍVIDA TRIBUTÁRIA COMO “OBSTÁCULO” À RECUPERAÇÃO DA EMPRESA}

O instrumento padrão de recuperação de empresas, na Lei n. 11.101, de 2005, como visto, é a novação das dívidas entre credores e devedor. Na recuperação judicial, os credores, em assembleia-geral, devem deliberar sobre as formas de pagamento propostas pelo devedor e, em havendo aprovação, submeter-se ao recebimento dos valores devidos em prazos e condições especiais. No caso da recuperação extrajudicial, a negociação dar-se-á diretamente entre o devedor e seus credores - sem a formação da assembleia.

A Lei de Recuperação de Empresas, contudo, não inclui a Fazenda Pública no rol de credores - ou classes de credores - autorizados a compor a assembleia-geral de que trata o art. 41 (aplicável exclusivamente aos processos de falência e recuperação judicial). No mesmo sentido, o diploma legal em comento retira expressamente do credor tributário a possibilidade de negociar com o devedor qualquer plano de recuperação extrajudicial (art. 161, § $1^{\circ}$ ).

Se se somarem à virtual impossibilidade de negociação do crédito tributário as disposições segundo as quais (i) as execuções fiscais não são suspensas pelo deferimento da recuperação judicial (LRE, art. $6^{\circ}, \S 7^{\circ}$ ) e (ii) o deferimento da recuperação judicial depende da apresentação de certidões negativas - ou positivas com efeitos de negativa - de créditos tributários (LRE, art. 57), pode-se chegar à conclusão de que a Fazenda Pública representa um dos maiores entraves à manutenção das atividades das empresas em crise. Some-se a isso o fato de que, em regra, as entidades que enfrentam problemas para pagar credores privados apresentam também pendências perante pelo menos uma das 3 (três) esferas federativas. Para continuar suas atividades, assim, as empresas em crise devem sanear, em primeiro lugar, suas pendências perante o Fisco.

Para compensar a exigência de quitação prévia de tributos, a leiestabelece um benefício ao empresário em crise. Estamos falando do parcelamento especial para empresas em recuperação judicial, prescrito no $\S 3^{\circ}$ do art. 155-A, do Código Tributário Nacional (na redação dada pela Lei Complementar n. 118, de 2005). De acordo com referida disposição, caberá aos diversos Entes da Federação estabeleceram modalidades de parcelamento de créditos específicas para agentes econômicos em recuperação judicial, mais benéficas do que as chamadas modalidades ordinárias, facultadas a todos os devedores.

Parte da doutrina considera que as disposições normativas que condicionam o deferimento da recuperação judicial ao pagamento ou parcelamento de tributos seriam inconstitucionais, por violarem os princípios gerais da atividade econômica, em especial, a livre iniciativa e a função social da propriedade privada. 
Machado (2005, p. 69), nessa direção, chega a afirmar que "quanto maior a iniciativa privada em determinada localidade, maior o progresso econômico, diante do aquecimento da economia causado a partir da geração de empregos", e que o "Estado deve contribuir para que as empresas em crise se recuperem". Para o referido professor, "não se justifica que dívidas tributárias sejam impedimento à recuperação".

Para Souza Júnior (2008, p. 149), a exigência de certidões negativas - ou positivas com efeitos de negativa - "é inconstitucional, posto que suas normas são intrinsecamente irracionais em relação ao texto constitucional, importam em verdadeira sanção política e são absolutamente desproporcionais".

Campinho (2012, p. 182), por sua vez, advoga a tese de que a apresentação de certidão não pode obstar a recuperação nos casos em que decorrer de fato alheio à vontade da empresa, e que a ausência de exibição do referido documento, em hipótese alguma pode acarretar a falência da empresa em crise, por falta de previsão legal. Argumenta, ademais, que o "Direito do Estado de exigir o crédito deve ser conjugado com o dever de promover o desenvolvimento econômico e social do país".

Brechbühler e Brechbühler (2013, p. 247), com base nas mesmas premissas apresentadas acima, defendem que, "[na] concretização dos princípios da função social da empresa e da função social da propriedade, o juiz não precisa se limitar ao que fixado nas leis de parcelamento, podendo deferir plano de pagamento diverso do apresentado pelo credor".

Com amparo no ideal de preservação da empresa, em razão de sua função social, consolidou-se, no âmbito do Superior Tribunal de Justiça, como se percebe da análise do acórdão do Recurso Especial 1187404 (BRASIL, 2013), o entendimento segundo o qual, enquanto não promulgadasas leis específicas de parcelamento especial tributário para empresas em recuperação judicial - exigidas pelo art. 155-A, $\S \S 3^{\circ}$ e $4^{\circ}$, do Código Tributário Nacional - tornar-se-ia sem efeito a exigência de apresentação de certidões contida no art. 57 da Lei de Recuperação de Empresas, autorizando-se o deferimento da recuperação independentemente do montante inscrito em dívida ativa.

O mesmo Superior Tribunal de Justiça, também sob o fundamento da necessidade de se conferir maior eficácia ao princípio da função social da empresa, pacificou a tese de que, embora o deferimento do processamento da recuperação judicial não seja capaz de suspender, por si só, as execuções fiscais ajuizadas pela Fazenda Pública (LRE, art. $6^{\circ}, \S 7^{\circ}$ ), eventuais constrições patrimoniais (penhoras, arrestos etc.) devem ser obstadas sempre que tais atos representarem óbices relevantes à continuidade da atividade empresarial. Competiria ao juízo da recuperação, nos termos, dentre outros, do Acórdão proferido no Agravo Interno em Recurso Especial n. 1612859 (BRASIL, 2017 a), casuisticamente, analisar quais penhoras poderiam ser concretizadas e quais não poderiam².

Os principais obstáculos legais à recuperação da empresa, referentes às dívidas contraídas junto à Fazenda Pública, como se percebe, vêm sendo afastados pelos Tribunais pátrios, via de regra, com supedâneo nas lições doutrinárias que postulam maior eficácia ao princípio da preservação da empresa, já tendo sido até mesmo ajuizada - pelo Distrito Federal Ação Declaratória de Constitucionalidade (ADC 46) com vistas ao reconhecimento da validade do supracitado art. 57 da LRE.

$\mathrm{Na}$ prática, embora mantida, no plano jurisprudencial, a exigência de extinção ou suspensão da exigibilidade do crédito tributário como requisito para deferimento da recuperação - sobretudo após a edição de diversas leis federal, estaduais e municipais sobre parcelamento especial para empresas em recuperação judicial -, os Entes vêm sendo impedidos de cobrar suas dívidas, haja vista que grande parte das execuções fiscais são suspensas sob o fundamento de que

${ }^{2}$ Dentre outros, confira-se: (BRASIL, 2016 a); (BRASIL, 2016, b).

Revista de Direito Brasileira | Florianópolis, SC | v. 23 | n. 9 | p. 410-424 |Mai./Ago. 2019 
as constrições atrapalham o regular andamento da recuperação. No confronto (aparente) entre livre exercício da atividade econômica e tributação, vem-se conferindo primazia ao primeiro.

Ocorre que, ao ignorar prescrições legais expressas e tentar fazer justiça, mediante implementação direta de princípio jurídico (função social da empresa), o Poder Judiciário acaba por impedir a concretização da ordem econômica normativa almejada pelo Constituinte. É sobre isso que se discorrerá na próxima seção.

\section{SOLIDARIEDADE, DEVER FUNDAMENTAL DE PAGAR TRIBUTOS E A COMPOSIÇÃO DOS INTERESSES FAZENDÁRIOS NO CURSO DO PROCESSO DE RECUPERAÇÃO JUDICIAL}

Quando se afirma que uma dívida de natureza tributária não pode obstar o deferimento de um pedido de recuperação judicial, quando se autoriza, ao arrepio da lei, a suspensão ( por prazo indefinido) dos processos de execução fiscal de créditos tributários sob o fundamento de que eventuais constrições patrimoniais inviabilizariam a recuperação da empresa e quando se insinua que o Estado, diante de uma empresa em crise, não deve se preocupar com a questão tributária, mas com a recuperação de um importante instrumento de desenvolvimento social, ignoram-se três premissas básicas de todo e qualquer Estado Social: em primeiro lugar, a de que o Estado é um dos agentes centrais do desenvolvimento, em segundo lugar, a de que todos os direitos - de qualquer dimensão - têm um custo e, em terceiro lugar, a de que os recursos para fazer frente a esses custos vêm, na sua maioria, da arrecadação de tributos.

Ainda que no Estado Democrático e Social de Direito a construção da sociedade almejada seja fruto tanto da participação do Poder Público (solidariedade vertical) quanto da sociedade civil (solidariedade horizontal), incluindo-se, aqui, os agentes econômicos empresariais, não há como se atribuir à segunda um papel de total prevalência em relação à primeira, como parecem querer fazer crer os autores mencionados na seção anterior. Não há como se inverter, dizendo de outra forma, o sistema de privilégios do crédito público em favor do crédito privado (SILVA, 2014, p. 147). Como bem pondera Comparato (2014, p. 125), quando a Constituição "declara que a ordem social tem por objetivo a realização do bem-estar e da justiça social (art. 193), ela não está certamente autorizando uma demissão do Estado, como órgão encarregado de guiar e dirigir a nação em busca de tais finalidades".

Para que o Estado exerça a missão a que se fez menção no parágrafo anterior, o que envolve o asseguramento de direitos das mais variadas dimensões, é indispensável que os agentes privados, além de pautarem suas atividades no ideal do bem comum, dotem o Poder Público dos meios materiais necessários à garantia dos supracitados direitos (TORRES, 1991, p. 97 e ss.). É dizer, o exercício da solidariedade horizontal envolve não só uma conduta voltada à consecução dos ideais republicanos, mas também o auxílio material ao Estado para que este possa proporcionar o alcance dos referidos objetivos.

Isso se dá pelo fato de que apenas o Estado pode assegurar direitos, e de que todos os direitos têm um custo. No caso dos direitos sociais, ou de segunda dimensão, essa afirmativa é mais facilmente perceptível, já que sua própria concretização depende de uma postura ativa do Estado, como acontece com os direitos à saúde, à educação e à cultura. Contudo, também os direitos de primeira dimensão, geralmente associados a uma conduta meramente negativa do Estado, quando violados, demandam uma atuação incisiva do Poder Público, com vistas à sua proteção - seja mediante o uso da força pública ou mesmo por meio de um processo judicial (SUSTEIN; HOLMES, 2000, p. 449). De nada adiantaria falar-se em direitos de propriedade, privacidade e liberdade, caso não se dotasse o Estado de instrumentos para efetivação de tais direitos em situações de violação.

Sobre o assunto, indispensáveis as palavras de Sustein e Holmes (2000, p. 449): 
Rights are costly because remedies are costly. Enforcement is expensive, especially uniform and fair enforcement; and legal rights are hollow to the extent that they remain unenforced. Formulated differently, almost every right implies a correlative duty, and duties are taken seriously only when dereliction is punished by the public power drawing on the public purse. There are no legally enforceable rights in the absence of legally enforceable duties, which is why law can be permissive only by being simultaneously obligatory. That is to say, personal liberty cannot be secured merely by limiting government interference with freedom of action and association. No right is simply a right to be left alone by public officials. ${ }^{3}$

Os recursos que possibilitam ao Estado proporcionar à sociedade os direitos (das mais diversas dimensões) mencionados acima advêm, em grande medida, da própria sociedade, mediante pagamento de tributos, daí falar-se em um dever fundamental de pagar tributos. Esse dever fundamental, nas palavras de Nabais (2010, p. 120), "tem por destinatários, não todos os cidadãos de um estado, mas apenas os fiscalmente capazes, incluindo-se neles, de um lado, as pessoas (ou organizações) colectivas e, de outro, mesmo os estrangeiros e apátridas".

Nas ordens jurídicas positivas, o dever fundamental de pagar tributos costuma decorrer das disposições constitucionais que estabelecem o princípio da capacidade contributiva (MOSCHETI, 1980, p. 109), de acordo com o qual contribuirão em maior medida para o bemestar social - falando em termos de valores monetários - aqueles que têm melhores condições de fazê-lo, ainda que sejam beneficiados em menor medida, num segundo momento, pelos serviços prestados pelo Estado. A capacidade contributiva, por sua vez, representa manifestação, no campo tributário, do princípio da solidariedade. Nas palavras de Tipke e Yamashita (2002, p. 18), "[a] justiça fiscal é o valor supremo do Estado de Direito dependente de impostos e, ao mesmo tempo, o valor supremo da comunidade dos contribuintes".

Criado o tributo, por meio de lei, e verificado o fato signo-presuntivo de riqueza (BECKER, 1998, p. 503 e ss.), incumbirá ao sujeito beneficiário da operação recolher recursos ao Estado, em cumprimento ao dever fundamental supracitado. Assim, realizada uma operação mercantil, caberá ao alienante - em regra - recolher aos cofres públicos o montante equivalente ao ICMS; auferida renda, deverá o beneficiário pagar o imposto de renda devido; prestado onerosamente um serviço (que não se enquadre na materialidade do ICMS), surgirá para o prestador a obrigação referente ao imposto sobre serviços.

Para que uma empresa cumpra sua função social, é indispensável que, além de respeitar os princípios constitucionais que regem a atividade econômica, cumpra com seu dever fundamental de pagar tributos. Nenhum agente econômico pode continuar funcionando caso o pressuposto para o desenvolvimento dessa atividade seja o não pagamento de tributos. Nas palavras de Nabais (2010, p. 132), "não há lugar a um qualquer (pretenso) direito fundamental de não pagar impostos, como o radicalismo das reivindicações de algumas organizações de contribuintes ou a postura teórica de alguns jusfiscalistas mais inebriados pelo liberalismo económico (...) parecem dar a entender".

\footnotetext{
${ }^{3}$ Em português: “Os direitos são dispendiosos porque os remédios são caros. A execução é dispendiosa, especialmente a aplicação uniforme e justa; e os direitos legais são vazios na medida em que permanecem sem garantia. Formulado de forma diferente, quase todos os direitos implicam um dever correlativo, e os deveres são levados a sério apenas quando o abandono é punido pelo poder público custeado pela Fazenda Pública. Não existem direitos legalmente exigíveis na ausência de obrigações legalmente exigíveis, razão pela qual a lei só pode ser permissiva ao ser simultaneamente obrigatória. Ou seja, a liberdade pessoal não pode ser assegurada apenas pela limitação da interferência do governo com a liberdade de ação e associação. Nenhum direito é simplesmente um direito de ser deixado sozinho por funcionários públicos” (tradução livre).
} 
A livre iniciativa pressupõe a livre concorrência, que, por sua vez, dentre outras coisas, demanda que os agentes econômicos possuam igualdade de oportunidade de competir (BOMFIM, 2011, p. 179), algo obviamente inexistente quando algumas empresas estão sujeitas à tributação e outras não, fora das hipóteses legalmente estabelecidas. A empresa que reiteradamente deixa de pagar tributos, sobretudo num país que tributa fortemente o consumo e a geração de riquezas, possui vantagem concorrencial significativa em relação às demais (MARTINS, 2005, p. 674).

Não se está aqui a defender a desimportância da atividade empresarial para o desenvolvimento do país, a complexidade do sistema tributário nacional, tampouco a elevada tributação incidente sobre as operações de circulação de bens e asprestações de serviços ${ }^{4}$, mas apenas, à luz do modelo de Estado adotado em 1988, a validade da opção legislativa decondicionar o deferimento da recuperação judicial à extinção ou à suspensão da exigibilidade do crédito tributário em conformidade com critérios objetivamente fixados em lei - critérios esses, no que diz respeito ao parcelamento do crédito tributário, necessariamente mais vantajosos.

O legislador, ao condicionar o deferimento da recuperação à extinção do crédito tributário - ou à suspensão de sua exigibilidade -, não proíbe que o Ente público conceda benefícios tributários à empresa em crise, mas apenas indica que esses benefícios não podem ser livremente pactuados entre o agente econômico e o representante do Ente estatal, uma vez que apenas quem tem o poder de tributar, isto é, o órgão legislativo do Ente (constitucionalmente) competente, tem o poder de isentar. Não de outra forma, dispõe a Constituição de 1988 expressamente que "[q]ualquer subsídio ou isenção, redução de base de cálculo, concessão de crédito presumido, anistia ou remissão, relativos a impostos, taxas ou contribuições, só poderá ser concedido mediante lei específica, federal, estadual ou municipal, que regule exclusivamente as matérias acima enumeradas" (art. 150, $\S 6^{\circ}$ ).

\section{CONCLUSÃO}

Diante de todo o exposto, pode-se concluir que são válidas as prescrições legais que condicionam o deferimento da recuperação judicial à quitação - ou à suspensão da exigibilidade - dos tributos devidos pela empresa em crise.

Ainda que se reconheça a relevância do exercício da atividade empresarial para o alcance dos objetivos fundamentais republicanos, quais sejam a construção de uma sociedade livre, justa e solidária, a garantia do desenvolvimento nacional, a erradicação da pobreza e da marginalização e a redução das desigualdades sociais e regionais e a promoção do bem de todos, não há como se atribuir à iniciativa privada, em detrimento do Poder Público,preponderância quase absoluta para o desempenho desse mister. Em um Estado Democrático e Social de Direito, como o inaugurado em 1988, é atribuição precípua da entidade estatal garantir aos seus titulares os direitos - de quaisquer dimensões - elencados na Constituição. Para tanto, e considerando que todo direito tem um custo, faz-se indispensável a obtenção de recursos junto aos particulares, o que se dá, geralmente, pela arrecadação de tributos, daí falar-se em um dever fundamental de pagar tributos.

Advogar a tese de que a prescrição legal que condiciona o deferimento da recuperação judicialà extinção do crédito tributário, ou à suspensão de sua exigibilidade, está em conformidade com a Constituição, não equivale a subestimar a importância da atividade econômica, tampouco defender o modelo de tributação vigente no país, mas apenas, à luz do

\footnotetext{
${ }^{4}$ O Brasil, em 2015, foi o segundo país, dentre os integrantes da Organização para Cooperação e Desenvolvimento Econômico - OCDE, que mais tributou operações relativas à circulação de bens e prestações de serviços, perdendo apenas para a Hungria. Por outro lado, no que diz respeito à tributação de renda, lucros e ganhos de capital, o país encontra-se na $34^{a}$ (trigésima quarta) posição dentre os integrantes da OCDE. Nesse sentido, confira-se: (BRASIL, $2017 \mathrm{~b})$.
}

Revista de Direito Brasileira | Florianópolis, SC | v. 23 | n. 9 | p. 410-424 |Mai./Ago. 2019 
Estado inaugurado em 1988, defender que um crédito da relevância do tributário não pode ficar sujeito ao mesmo regime de novações a que se sujeitam os créditos tributários descritos na Lei n. 11.101, de 2005, tampouco em posição de inferioridade em relação aos mencionados créditos.

Pela relevância do cumprimento desse dever fundamental, bem como levando-se em conta o fato de que a recuperação judicial tem por objetivo a proteção da ordem econômica, defendemos que as condições para equacionamento do passivo tributário da empresa em crise sejam objetivamente fixadas em lei, ainda que referida norma seja mais benéfica do que aquela aplicável aos demais agentes econômicos.

\section{REFERÊNCIAS}

BITENCOURT NETO, Eurico. Estado social e administração pública de garantia. Revista de Direito Econômico e Socioambiental, Curitiba, v. 8, n. 1, p. 289-302, jan./abr. 2017.

BOMFIM, Diego. Tributação e livre concorrência. São Paulo: Saraiva, 2011.

BONAVIDES, Paulo. Curso de direito constitucional. 28. ed. atual. São Paulo: Malheiros, 2013. Do estado liberal ao estado social. 6. ed. rev. e ampl. São Paulo: Malheiros, 1996. . Teoria do Estado. 3. ed. rev. e ampl. São Paulo: Malheiros, 1995.

BRASIL. Superior Tribunal de Justiça. REsp 1187404/MT, Rel. Ministro Luis Felipe Salomão, Corte Especial, julgado em 19/06/2013, publicado no Diário da Justiça de 21/08/2013.

BRASIL. Superior Tribunal de Justiça. AgInt no AREsp 779.631/DF, Rel. Ministra Diva Malerbi (Desembargadora Convocada TRF $3^{\text {a }}$ Região), Segunda Turma, julgado em 17/5/2016, publicado no Diário da Justiça de 24/5/2016.

BRASIL. Superior Tribunal de Justiça. AgRg no REsp 1.571.394/RS, Rel. Ministro Herman Benjamin, Segunda Turma, julgado em 3/3/2016, Publicado no Diário da Justiça de 24/5/2016.

BRASIL. Superior Tribunal de Justiça. AgInt no REsp 1612859/RS, Rel. Ministro Francisco Falcão, Segunda Turma, julgado em 08/08/2017, publicado no Diário da Justiça de 17/08/2017.

BRASIL. Receita Federal do Brasil. Carga tributária no Brasil 2016: análise por tributos e bases de incidência. Publicado em dezembro de 2017. Disponível em http://idg.receita.fazenda.gov.br/dados/receitadata/estudos-e-tributarios-e-aduaneiros/estudos-eestatisticas/carga-tributaria-no-brasil/carga-tributaria-2016.pdf. Acesso em 29/07/2018.

BRECHBÜHLER, Gustavo; BRECHBÜHLER, Guilherme. Ativismo judicial, recuperação de empresas e parcelamento fiscal: Busca pela efetividade do art. 68 da lei 11.101/2005. In. Revista Tributária e de Finanças Públicas. Ano 21. N. 112. Set./out. 2013. p. 231-266.

CAMPINHO, Sérgio. Falência e recuperação de empresa: o novo regime da insolvência empresarial. 6. ed. rev. e atual. Rio de Janeiro: Renovar, 2012.

CARVALHO, Paulo de Barros. Curso de direito tributário. 14. ed., revista e atualizada. São Paulo: Saraiva, 2012. 
CASTRO, Eduardo Moreira Lima Rodrigues de. Tributação e fazenda pública: meios alternativos de cobrança de tributos. Curitiba: Juruá, 2016.

COELHO, Fábio Ulhoa. Comentários à lei de falências e recuperação de empresas. 9. ed. São Paulo: Saraiva, 2013.

COÊLHO, Sacha Calmon Navarro. Curso de direito tributário brasileiro. 9. ed. Revista e atualizada de acordo com o Código Civil de 2002. Rio de Janeiro: Forense, 2007.

COMPARATO, Fábio Konder. Estado, empresa e função social. Revista Doutrina Civil Primeira seção. RT/Fasc. Civ.: 1996.

COPETTI NETO, Alfredo; GARCIA, Mariana da Silva. Um ensaio sobre os fundamentos liberais-sociais da Constituição Brasileira de 1988. Revista de Direito Brasileira, São Paulo, SP, v. 18, n. 7, p. 134-148, Set./Dez. 2017.

FIGUEIREDO, Leonardo Vizeu. Lições de Direito Econômico. 4. ed. Rio de Janeiro: Forense, 2011.

FORNARI, Homero José Nardim. A função social da empresa: elemento decisivo na recuperação judicial. Revista de Direito Empresarial - RDEmp, Belo Horizonte, ano 12, n. 2, maio/ago. 2015. Disponível em: <http://www.bidforum.com.br/PDI0006.aspx?pdiCntd=236820>. Acesso em: 7 set. 2017.

GARCIA, Rodrigo Saraiva Porto; SANT'ANNA, Leonardo da Silva. O abuso do direito de voto pelo credor na recuperação judicial. Revista de Direito Empresarial-RDEmp, Belo Horizonte, ano 14, n. 02, maio/ago. 2017. Disponível em:

<http://www.bidforum.com.br/PDI0006.aspx?pdiCntd=248188>. Acesso em: 11 fev. 2018.

GRAU, Eros Roberto. A ordem econômica na Constituição de 1988. 15. ed. rev. e atual. São Paulo: Malheiros, 2012.

GUERRA FILHO, Willis Santiago. Processo constitucional e direitos fundamentais. São Paulo, Editora RCS, 2005.

HOLMES, Stephan; SUSTEIN, Cass R. The cost of rights: why liberty depends on taxes [kindle edition], 2000.

LAKATOS, Eva Maria; MARCONI, Marina de Andrade. Metodologia científica. 6. ed. São Paulo: Atlas, 2011.

LIMA, Gabriela Eulálio de; OLIVEIRA, Lourival José de. Uma ordem econômica justa e equilibrada: o ativismo judicial em prol da valorização do trabalho humano. Revista de Direito Brasileira, São Paulo, SP, v. 19, n. 8, p. 221 - 237 |Jan./Abr. 2018.

MACHADO, Hugo de Brito. Dívida tributária e recuperação judicial da empresa. In. Revista Dialética de Direito Tributário 120/69. São Paulo: Dialética, set. 2005. 
MARMELSTEIN, George. Curso de direitos fundamentais. 6. ed. revista, atualizada e ampliada. São Paulo: Atlas, 2016.

MARTINS, Ives Gandra da Silva. Obrigações acessórias tributárias e a disciplina jurídica da concorrência. In: Princípios e limites da tributação. Roberto Ferraz (org.). São Paulo: Quartier Latin, 2005, p. 668-682.

MENDES, Gilmar Ferreira; COELHO, Inocêncio Mártires; BRANCO, Paulo Gustavo Gonet. Curso de direito constitucional. 5. ed. revista e atualizada. São Paulo: Saraiva, 2010.

MOSCHETTI, Francesco. El principio de capacidad contributiva. Tra. de Juan M. Calero Gallego y Rafael Navas Vazques. Madrid: Instituto de Estudios Fiscales, 1980.

MOREIRA NETO, Diogo de Figueiredo. O Direito Administrativo do século XXI: um instrumento de realização da democracia substantiva. Revista de Direito Administrativo e Constitucional-A\&C. Ano 11, n. 45. Jul/Set 2011. Belo Horizonte, Forum.

NABAIS, José Casalta. O dever fundamental de pagar impostos: contributo para a compreensão constitucional do estado fiscal contemporâneo. Coimbra: Almedina, 2004.

PIKETTY, Thomas. O capital no século XXI. Traduçãode Monica Baumgarten de Bolle. Rio de Janeiro: Intrínseca, 2014.

PISANI, Carolina Dorneles. A cobrança tributária em face de empresa em processo de recuperação judicial: uma reflexão à luz de recente julgado do STJ e da edição da lei 13.043/2014. In: Revista Tributária e de Finanças Públicas. Ano 25. vol. 123. Jul - Ago 2015, p. 209-222.

SALOMÃO FILHO, Calixto. Regulação da Atividade Econômica (princípios e fundamentos jurídicos). São Paulo: Malheiros, 2001.

SARLET, Ingo Wolfgang; MARINONI, Luiz Guilherme; MITIDIERO, Daniel. Curso de direito constitucional. 2. ed. revista, atualizada e ampliada. São Paulo: Editora Revista dos Tribunais, 2013.

SEPULCRI, Nayara Tataren. O princípio da solidariedade no sistema constitucional tributário brasileiro. 262 f. Dissertação (Mestrado em Direito do Estado), Universidade Federal do Paraná. Curitiba, 2013.

SILVA, Juliana Giovanetti Pereira da. A publicização do Direito Comercial e a função social da empresa. In: Revista de Direito Empresarial - RDEmp, Belo Horizonte, ano 12, n. 1, p, jan./abr. 2015. Disponível em: <http://www.bidforum.com.br/PDI0006.aspx?pdiCntd=232503>. Acesso em: 7 set. 2017 .

SILVA, Luiz Henrique Teixeira da. Execução fiscal aplicada: análise pragmática do processo de execução fiscal. 3. ed. rev. atual. e ampl., Salvador: Ed. JusPodivm, 2014. 